\title{
Kazachstania siamensis sp. nov., an ascomycetous yeast species from forest soil in Thailand
}

Correspondence

Savitree Limtong

fscistl@ku.ac.th

\author{
Savitree Limtong, ${ }^{1}$ Wichien Yongmanitchai, ${ }^{1}$ Moe Moe Tun, ${ }^{1,2}$ \\ Hiroko Kawasaki ${ }^{3}$ and Tatsuji Seki ${ }^{3}$ Bangkok 10900, Thailand
${ }^{2}$ Department of Botany, University of East Yangon, Thanyin Township, Myanmar
${ }^{3}$ The International Center for Biotechnology, Osaka University, 2-1 Yamada-oka, Suita-City, Osaka 565-0871, Japan \\ ${ }^{1}$ Department of Microbiology, Faculty of Science, Kasetsart University, 50 Paholyothin Rd,
}

\begin{abstract}
Two strains (S-34 ${ }^{\top}$ and S-35) of a novel ascomycetous yeast species belonging to the genus Kazachstania were isolated from soil from a mixed deciduous forest in Amphoe Wang Nam Khiao, Nakhon Ratchasima Province, Thailand. The D1/D2 domains of the large-subunit rDNA sequences of the two strains were identical and also indicated a close relationship with respect to Kazachstania aquatica, Kazachstania unispora, Kazachstania aerobia, Kazachstania servazzii and Kazachstania solicola. The most closely related species, $K$. aquatica, has 14 nucleotide substitutions and three gaps in 566 nt. The phenotypic characteristics of the two strains were typical of those of members of the genus Kazachstania. These characteristics include the formation of a single globose ascospore in an unconjugated and persistent ascus, multilateral budding, the absence of arthrospores and ballistospores, the fermentation of glucose, the inability to assimilate nitrate, negative diazonium blue $B$ and urease reactions, and the presence of ubiquinone Q-6. The novel strains can be distinguished from $K$. aquatica on the basis of a number of phenotypic characteristics and represent a novel species in the genus Kazachstania, for which the name Kazachstania siamensis sp. nov. is proposed. The type strain is $\mathrm{S}-34^{\top}\left(=\mathrm{CBS} 10361^{\top}=\mathrm{NBRC}\right.$ $101968^{\top}=$ BCC $21230^{\top}$ ).
\end{abstract}

The genus Kazachstania, which is a member of the family Saccharomycetaceae, was first described on the basis of the single species, Kazachstania viticola (Zubkova, 1971). In 2003, several species previously assigned to Saccharomyces and Kluyveromyces were transferred to Kazachstania on the basis of a multigene sequence analysis that included genes of the rDNA repeat (18S, 26S, internal transcribed spacer), single-copy nuclear genes (translation elongation factor $1 \alpha$, actin-1, RNA polymerase II) and mitochondrially encoded genes [small-subunit (SSU) rDNA, cytochrome oxidase II] (Kurtzman, 2003; Kurtzman \& Robnett, 2003). Recently, three non-pathogenic species (Lu et al., 2004; Wu \& Bai, 2005) and four pathogenic species (Kurtzman et al., 2005) of the genus Kazachstania were described. During an investigation of yeasts in soil, two novel strains, $\mathrm{S}-34^{\mathrm{T}}$ and $\mathrm{S}-35$, were isolated and found to represent a novel species of the

Abbreviations: LSU, large subunit; SSU, small subunit.

The GenBank/EMBL/DDBJ accession numbers for the D1/D2 domains of the LSU rDNA sequences of strains S-34 ${ }^{\top}$ and S-35 are AB258462 and AB258463, respectively.

A neighbour-joining phylogenetic tree based on SSU rDNA sequences is available as a supplementary figure in IJSEM Online. genus Kazachstania. The novel species is closely related to Kazachstania aquatica, Kazachstania aerobia, Kazachstania solicola, Kazachstania servazzii and Kazachstania unispora; the first three of these were described only recently ( $\mathrm{Lu}$ et al., 2004; Wu \& Bai, 2005) and the last two were transferred from the genus Saccharomyces (Kurtzman, 2003; Kurtzman \& Robnett, 2003). K. aquatica and K. solicola were identified as novel species by sequence analysis of the SSU rDNA, the internal transcribed spacer region (including $5.8 \mathrm{~S}$ rDNA) and the large-subunit (LSU) D1/D2 domain (Wu \& Bai, 2005), whereas K. aerobia was circumscribed on the basis of the internal transcribed spacer and D1/D2 sequences and electrophoretic karyotypes (Lu et al., 2004). K. servazzii and $K$. unispora were transferred from the genus Saccharomyces on the basis of a multigene sequence analysis (Kurtzman, 2003; Kurtzman \& Robnett, 2003).

Strains S- $34^{\mathrm{T}}$ and S-35 were isolated from two soil samples collected from a mixed deciduous forest in Amphoe Wang Nam Khiao, Nakhon Ratchasima Province, Thailand, by using an enrichment technique. Each soil sample (5 g) was added to $50 \mathrm{ml}$ acidified yeast extract/malt extract (YM) broth $(0.3 \%$ yeast extract, $0.3 \%$ malt extract, $0.5 \%$ peptone, $1 \%$ glucose; adjusted to $\mathrm{pH} 3.7-3.8$ with $1 \mathrm{M}$ 
$\mathrm{HCl}$ ) supplemented with $0.025 \%$ sodium propionate and $200 \mathrm{mg}$ chloramphenicol $\mathrm{l}^{-1}$ in a $250 \mathrm{ml}$ Erlenmeyer flask and incubated at room temperature for 3-4 days on a rotary shaker. The enrichment culture was then spread out on YM agar supplemented with $0.025 \%$ sodium propionate and $200 \mathrm{mg}$ chloramphenicol $\mathrm{l}^{-1}$. When necessary, colonies were restreaked onto YM agar.

The sequences of the D1/D2 domain of the LSU rDNA and the SSU rDNA were determined from PCR products from genomic DNA extracted from yeast cells by using a slightly modified version of the method described by Lachance $e t$ al. (1999). The D1/D2 domain of the LSU rDNA was amplified by a PCR with the forward primer NL-1 and the reverse primer NL-4 (O'Donnell, 1993); amplification of the SSU rDNA was done with the forward primer P1 and the reverse primer P2 (Sjamsuridzal et al., 1997). The PCR product was checked by agarose gel electrophoresis, purified using the QIAquick purification kit (Qiagen) and cycle-sequenced using the $\mathrm{ABI}$ BigDye terminator cycle sequencing kit, version 3.1 (Applied Biosystems), with the external primers NL-1 and NL-4 for the D1/D2 domain (Kurtzman \& Robnett, 1998) and eight primers, P1-P8, for the SSU rDNA (Yamada et al., 1999). The sequences were determined with an ABI PRISM 3100 automated DNA sequencer (Applied Biosystems) according to the instructions of the manufacturer. The sequences were compared pairwise by the BLASTN homology search program (Altschul et al., 1990) and were aligned with the sequences of related species retrieved from GenBank using the multiple alignment program CLUSTAL X, version 1.81 (Thompson et al., 1997). A phylogenetic tree was constructed from the evolutionary distance data according to the two-parameter method of Kimura (1980) and the neighbour-joining method (Saitou \& Nei, 1987). The robustness of the phylogenetic trees was estimated using bootstrap analysis (1000 replicates) (Felsenstein, 1985).

The strains were characterized morphologically, biochemically and physiologically according to the standard methods described by Yarrow (1998). Assimilation of nitrogen compounds was examined on solid media with starved inocula, using the method of Nakase \& Suzuki (1986). Growth at various temperatures was determined by cultivation on yeast extract/peptone/dextrose (YPD) agar ( $1 \%$ yeast extract, $2 \%$ peptone, $2 \%$ glucose and $2 \%$ agar). Ubiquinones were extracted from intact packed cells cultivated in YPD broth on a rotary shaker at $28^{\circ} \mathrm{C}$ for 24-48 $\mathrm{h}$ and then purified according to the method described by Yamada \& Kondo (1973). The isoprenologues were identified by HPLC using a Cosmosil (5C18; Waters) $4.6 \times 250 \mathrm{~mm}$ column and methanol/2-propanol $(2: 1)$ at $1 \mathrm{ml} \mathrm{min}{ }^{-1}$ as the elution system, with spectrophotometric detection (275 nm wavelength), according to the method of Kuraishi et al. (1985).

The sequences of the D1/D2 domains of the LSU rDNAs of strain S-34 ${ }^{\mathrm{T}}$ and S-35 were identical. The two strains clustered with $K$. aquatica, $K$. unispora, $K$. aerobia, $K$. servazzii and $K$. solicola with high bootstrap values and were separate from Saccharomyces species (Fig. 1) and as well as from the pathogenic species of the Kazachstania telluris complex (Kazachstania bovina, Kazachstania heterogenica, Kazachstania pintolopesii and Kazachstania slooffiae) recently described by Kurtzman et al. (2005) (data not shown). Strain S-34 ${ }^{\mathrm{T}}$ and S-35 showed $3 \%$ divergence (14 nucleotide substitutions and three gaps out of $566 \mathrm{nt}$ ) from $K$. aquatica, the closest species in terms of pairwise sequence similarity, indicating that the two strains could represent a novel species. According to Kurtzman \& Robnett (1998), yeast strains that show nucleotide substitution greater than $1 \%$ in the D1/D2 domain of the LSU rDNA usually represent different species. However, to confirm the novelty of the two strains, their SSU rDNA sequences were determined: they were found to be identical. The closest relative of the two strains in terms of pairwise sequence similarity was K. aquatica, which differed by nine nucleotide substitutions and three gaps out of $1781 \mathrm{nt}$. In the phylogenetic analysis based on the SSU rDNA sequences, the two novel strains clustered with K. aquatica, K. unispora, K. aerobia, K. servazzii and K. solicola (see Supplementary Fig. S1 available in IJSEM Online), which is similar to what is seen in the tree based on the D1/D2 LSU rDNA sequences. These results lend further support to the conclusion that the two strains represent a novel species closely related to $K$. aquatica.

Cells of strains $\mathrm{S}-34^{\mathrm{T}}$ and S-35 formed single globose ascospores in unconjugated and persistent asci (Fig. 2), proliferated by multilateral budding (Fig. 2), lacked arthrospores and ballistospores, fermented glucose but did not assimilate nitrate, gave negative reactions for the diazonium blue B and urease tests and contained Q-6 as

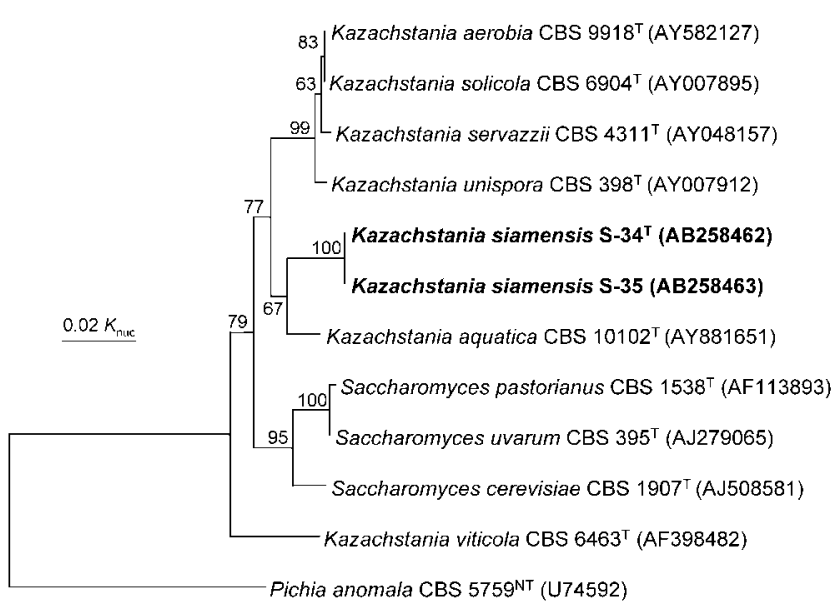

Fig. 1. Phylogenetic tree, based on the D1/D2 LSU rDNA, showing the placement of strains $\mathrm{S}-34^{\top}$ and $\mathrm{S}-35$ with respect to closely related species. The tree was constructed with the neighbour-joining method, based on approximately $600 \mathrm{nt}$, using Kimura's two-parameter distance correction. Numbers at branch points are bootstrap percentages derived from 1000 pseudoreplicates. 

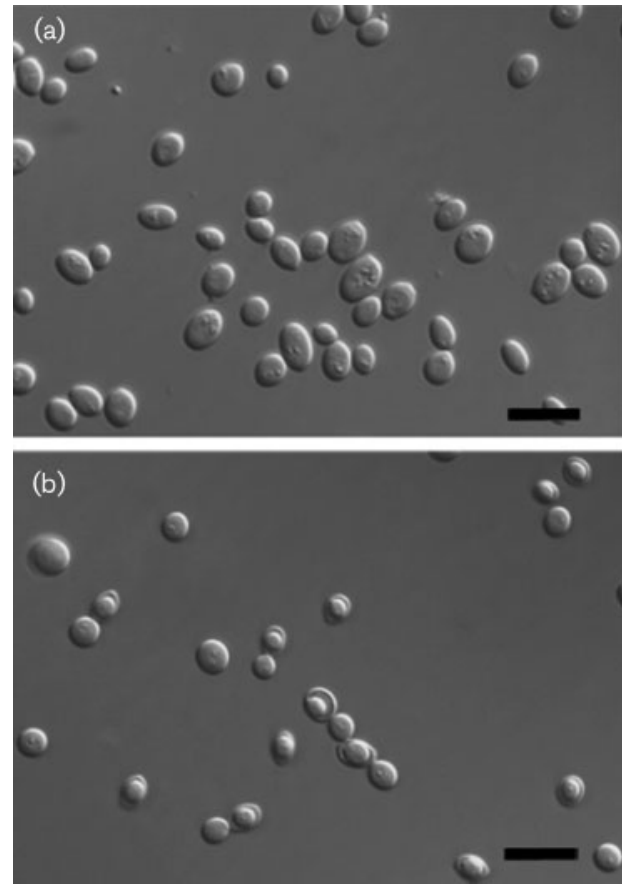

Fig. 2. Micrographs of strain $S-34^{\top}$ showing (a) vegetative cells grown on $\mathrm{YM}$ agar for 3 days at $28^{\circ} \mathrm{C}$ and (b) ascospores formed on Gorodkowa agar after 7 days at $28^{\circ} \mathrm{C}$. Bars, $10 \mu \mathrm{m}$.

the major ubiquinone. These characteristics fit well with those of species of the genus Kazachstania. The two strains also shared the same conventional taxonomic characteristics, as shown in Table 1. We conclude, therefore, that the two strains represent a single novel species of the genus Kazachstania, for which the name Kazachstania siamensis is proposed.

$K$. siamensis can be distinguished from $K$. aquatica, the species closest to it in the phylogenetic tree, on the basis of a number of phenotypic characteristics, as shown in Table 1.

\section{Latin diagnosis of Kazachstania siamensis Limtong, Yongmanitchai, Tun, Kawasaki et Seki sp. nov.}

In agaro YM post dies 3 ad $28^{\circ} \mathrm{C}$ cellulae ovoideae aut ellipsoideae, $(2.4-4.8 \times 2.9-8.1 \mu \mathrm{m})$, singulae, aut binae, per germinationem multipolarem reproducentes. Cultura cremea, butyrosa, initida, glabra, nitida et margine undulato. In agaro farinae Zea mays post dies 21 ad $28^{\circ} \mathrm{C}$ et agaro YM post dies 21 ad $25^{\circ} \mathrm{C}$ pseudomycelium nec mycelium non formantur. In agaro aceti et agaro Gorodkowa post dies 7 ad $28^{\circ} \mathrm{C}$ asci formantur. Asci inconjugatio fiunt. Ascosporae globosae, 1 in quoque asco. In medio liquido YM post unum mensem ad $28{ }^{\circ} \mathrm{C}$, sedimentum formantur et pellicula non formantur. Glucosum et galactosum (infirme) fermentatur at non maltosum, sucrosum, trehalosum, lactosum nec raffinosum. Glucosum, galactosum et trehalosum assimilantur at non L-sorbosum, D-ribosum, D-xylosum, L-arabinosum, D-arabinosum,
Table 1. Growth characteristics of the novel strains and $K$. aquatica

Results for strain S-35 were identical to those given for strain S$34^{\mathrm{T}}$. Data for $K$. aquatica were taken from Wu \& Bai (2005). Both taxa were positive for the fermentation of D-glucose but negative for the fermentation of D-maltose, sucrose, lactose and raffinose. L-Sorbose, D-ribose, D-xylose, L-arabinose, D-arabinose, L-rhamnose, sucrose, maltose, cellobiose, salicin, melibiose, lactose, raffinose, melezitose, inulin, soluble starch, glycerol, erythritol, ribitol, D-glucitol, D-mannitol, galactitol, myo-inositol, DL-lactate, succinic acid, citric acid, methanol, potassium nitrate and sodium nitrite were not assimilated by either taxon. For both taxa, growth did not occur in vitamin-free medium, growth occurred at 25, 30, 35 and $37^{\circ} \mathrm{C}$ and growth did not occur at $42^{\circ} \mathrm{C}$. For both taxa, the results for diazonium blue $\mathrm{B}$ colour and urease reactions were negative. +, Positive; -, negative; D, delayed positive; ND, no data available; $\mathrm{w}$, weak.

\begin{tabular}{|lcc|}
\hline Characteristic & Strain S-34 & K. aquatica \\
\hline Fermentation of D-galactose & $\mathrm{W}$ & + \\
Assimilation of: & & \\
D-Glucose & + & $\mathrm{W}, \mathrm{D}$ \\
D-Galactose & + & $\mathrm{W}, \mathrm{D}$ \\
Trehalose & + & $\mathrm{W}, \mathrm{D}$ \\
2-Ketogluconic acid & - & $\mathrm{ND}$ \\
D-Gluconic acid & - & $\mathrm{ND}$ \\
D-Glucuronic acid & - & $\mathrm{ND}$ \\
D-Galacturonic acid & - & $\mathrm{ND}$ \\
Ethanol & - & $\mathrm{W}, \mathrm{D}$ \\
Ethylamine hydrochloride & - & + \\
L-Lysine hydrochloride & - & + \\
Cadaverine & - & + \\
Growth at/with: & & - \\
$40{ }^{\circ} \mathrm{C}$ & + & $\mathrm{ND}$ \\
$0.01 \%$ Cycloheximide & + & $\mathrm{ND}$ \\
$0.1 \%$ Cycloheximide & + & $\mathrm{ND}$ \\
$50 \%$ Glucose & $\mathrm{W}$ & $\mathrm{ND}$ \\
$60 \%$ Glucose & - & $\mathrm{ND}$ \\
$10 \%$ NaCl $+5 \%$ glucose & - & \\
& & \\
\end{tabular}

L-rhamnosum, sucrosum, maltosum, cellobiosum, salicinum, melezitosum, inulinum, amylum solubile, glycerolum, erythritolum, ribitolum, glucitolum, D-mannitolum, galactitolum, inositolum, acidum 2-ketogluconicum, acidum D-gluconicum, acidum D-glucuronicum, acidum D-galacturonicum, acidum DL-lacticum, acidum succinicum, acidum citricum, methanolum nec ethanolum. Ammonium sulfatum assimilatur at non natrum nitrosum, kalium nitricum, ethylaminum, L-lysinum nec cadaverinum. Crescere potest in temperatura $40{ }^{\circ} \mathrm{C}$ at non in $42{ }^{\circ} \mathrm{C}$. Crescit in $0.01 \%$ cycloheximido, $0.1 \%$ cycloheximido et $50 \%$ glucosum (infirme). Non crescit in $60 \%$ glucosum nec $10 \% \mathrm{NaCl} / 5 \%$ glucosum (10:5). Ureum non hydrolysatur. Diazonium caeruleum B non respondens. Ubiquinonum majum: Q-6.

Typus stirpis S-34 ${ }^{\mathrm{T}}\left(=\mathrm{CBS} 10361^{\mathrm{T}}=\right.$ NBRC $101968^{\mathrm{T}}=\mathrm{BCC}$ $21230^{\mathrm{T}}$ ) isolatus e terea, Nakhon Ratchasima Provincia, 
Thailandia, conservatur in collectionibus culturarum quas Centraalbureau voor Schimmelcultures (Utrecht, The Netherlands), NITE Biological Resource Center, National Institute of Technology and Evaluation (Chiba, Japan) et BIOTEC Culture Collection, National Center for Genetic Engineering and Biotechnology, Thailand (Pathumthani, Thailand) deposita est.

\section{Description of Kazachstania siamensis Limtong, Yongmanitchai, Tun, Kawasaki \& Seki sp. nov.}

Kazachstania siamensis (si.am.en'sis. N.L. fem. adj. siamensis referring to Siam, the old name of Thailand, where the two strains were isolated).

After 3 days growth on $\mathrm{YM}$ agar at $28^{\circ} \mathrm{C}$, cells are ovoid to ellipsoid $(2.4-4.8 \times 2.9-8.1 \mu \mathrm{m})$ and occur singly or in pairs (Fig. 2). Budding is multilateral. Streak culture on YM agar after 3 days at $28^{\circ} \mathrm{C}$ is butyrous, cream-coloured, glossy, smooth and raised with undulate margins. In Dalmau plate culture on cornmeal agar at $28^{\circ} \mathrm{C}$ and YM agar at $25^{\circ} \mathrm{C}$ after 3 weeks, pseudohyphae and true hyphae are not formed. Neither arthrospores nor ballistospores are produced. Ascospores form on Forwell's acetate agar and Gorodkowa agar after 7 days at $28^{\circ} \mathrm{C}$; asci are unconjugated, persistent and each contain a single globose ascospore (Fig. 2). After 1 month in YM broth at $28^{\circ} \mathrm{C}$, sediment is present. A pellicle is not present during growth on the surface of assimilation medium. The major ubiquinone is Q-6. Phenotypic characteristics of the species are shown in Table 1.

The type strain, $\mathrm{S}-34^{\mathrm{T}}\left(\mathrm{CBS} 10361^{\mathrm{T}}=\mathrm{NBRC} 101968^{\mathrm{T}}=\mathrm{BCC}\right.$ $21230^{\mathrm{T}}$ ), was isolated from soil collected in a mixed deciduous forest in Amphoe Wang Nam Khiao, Nakhon Ratchasima Province, Thailand.

\section{Acknowledgements}

We are grateful to ICBiotech, Osaka University, Japan, and the National Research Council, Thailand, for financial and technical support. We thank Dr Tawatchai Sumpradit, Dr Sasitorn Jindamorakot, Ms Chutima Sringiew, Ms Suthida Tuntigumton and Ms Somjit Am-in for help with some of the experiments.

\section{References}

Altschul, S. F., Gish, W., Miller, W., Meyers, E. W. \& Lipman, D. J. (1990). Basic local alignment search tool. J Mol Biol 215, 403-410.

Felsenstein, J. (1985). Confidence limits on phylogenies: an approach using the bootstrap. Evolution 39, 783-791.

Kimura, M. (1980). A simple method for estimating evolutionary rates of base substitutions through comparative studies of nucleotide sequences. J Mol Evol 16, 111-120.

Kuraishi, H., Katayama-Fujimura, Y., Sugiyama, J. \& Yokoyama, T. (1985). Ubiquinone systems in fungi I. Distribution of ubiquinones in the major families of ascomycetes, basidiomycetes, and deuteromycetes, and their taxonomic implications. Trans Mycol Soc Jpn 26, 383-395.

Kurtzman, C. P. (2003). Phylogenetic circumscription of Saccharomyces, Kluyveromyces and other members of the Saccharomycetaceae, and the proposal of the new genera Lachancea, Nakaseomyces, Naumovia, Vanderwaltozyma and Zygotorulaspora. FEMS Yeast Res 4, 233-245.

Kurtzman, C. P. \& Robnett, C. J. (1998). Identification and phylogeny of ascomycetous yeasts from analysis of nuclear largesubunit (26S) ribosomal DNA partial sequences. Antonie van Leeuwenhoek 73, 331-371.

Kurtzman, C. P. \& Robnett, C. J. (2003). Phylogenetic relationships among yeasts of the 'Saccharomyces complex' determined from multigene sequence analysis. FEMS Yeast Res 3, 417-432.

Kurtzman, C. P., Robnett, C. J., Ward, J. M., Brayton, C., Gorelick, P. \& Walsh, T. J. (2005). Multigene phylogenetic analysis of pathogenic Candida species in the Kazachstania (Arxiozyma) telluris complex and description of their ascosporic states as Kazachstania bovina sp. nov., K. heterogenica sp. nov., K. pintolopsii sp. nov., and K. slooffiae sp. nov. J Clin Microbiol 43, 101-111.

Lachance, M. A., Bowles, J. M., Starmer, W. T. \& Baker, S. F. (1999). Kodamaea kadaduensis and Candida tolerans, two new ascomycetous yeast species from Australian Hibiscus flowers. Can J Microbiol 45, $172-177$.

Lu, H.-Z., Cai, Y., Wu, Z.-W., Jia, J.-H. \& Bai, F.-Y. (2004). Kazachstania aerobia sp. nov., an ascomycetous yeast species from aerobically deteriorating corn silage. Int J Syst Evol Microbiol 54, 2431-2435.

Nakase, T. \& Suzuki, M. (1986). Bullera megalospora, a new species of yeast forming larger ballistospores isolated from dead leaves of Oryza sativa, Miscanthus sinensis and Sasa sp. in Japan. J Gen Appl Microbiol 32, 225-240.

O'Donnell, K. (1993). Fusarium and its near relatives. In The Fungal Holomorph: Mitotic, Meiotic and Pleomorphic Speciation in Fungal Systematics, pp. 225-233. Edited by D. R. Reynolds \& J. W. Taylor. Wallingford, UK: CAB International.

Saitou, N. \& Nei, M. (1987). The neighbor-joining method: a new method for reconstructing phylogenetic trees. Mol Biol Evol 4, 406-425.

Sjamsuridzal, W., Tajiri, Y., Nishida, H., Thuan, T. B., Kawasaki, H., Hirata, A., Yokota, A. \& Sugiyama, J. (1997). Evolutionary relationships of members of the genera Taphrina, Protomyces, Schizosaccharomyces and related taxa within the Archiascomycetes: integrated analysis of genotypic characteristics. Mycoscience 38, 267-280.

Thompson, J. D., Higgins, D. G., Gibson, T. J., Plewniak, F., Jeanmougin, F. \& Higgins, D. J. (1997). The CLUSTAL_X windows interface: flexible strategies for multiple sequence alignment aided by quality analysis tools. Nucleic Acids Res 25, 4876-4882.

Wu, Z.-W. \& Bai, F.-Y. (2005). Kazachstania aquatica sp. nov. and Kazachstania solicola sp. nov., novel ascomycetous yeast species. Int J Syst Evol Microbiol 55, 2219-2224.

Yamada, Y. \& Kondo, K. (1973). Coenzyme Q system in the classification of the yeast genera Rhodotorula and Cryptococcus and the yeast-like genera Sporobolomyces and Rhodosporidium. J Gen Appl Microbiol 19, 59-77.

Yamada, Y., Kawasaki, H., Nagatsuka, Y., Mikata, K. \& Seki, T. (1999). The phylogeny of the catophilic yeasts based on the $18 \mathrm{~S}$ ribosomal RNA gene sequences: the proposals of Phaffomyces antillensis and Starmera caribaea, new combinations. Biosci Biotechnol Biochem 63, 827-832.

Yarrow, D. (1998). Methods for the isolation, maintenance and identification of yeasts. In The Yeasts, a Taxonomic Study, 4th edn, pp. 77-100. Edited by C. P. Kurtzman \& J. W. Fell. Amsterdam: Elsevier.

Zubkova, R. D. (1971). Genus novum Saccharomycetacearum e Kazachstania. Bot Mater Gerb Inst Bot Akad Nauk Kazakh SSR 7, 53 56 (in Russian). 